\title{
Highly sensitive VOC sensors using NiO-decorated ZnO nanowire networks: the effect of radial $p-n$ junction
}

\author{
Chan Woong Na, Hyung-Sik Woo and Jong-Heun Lee* \\ Department of Materials Science and Engineering, Korea University, \\ Anam-Dong, Seongbuk-Gu, Seoul, 136-713, Republic of Korea. \\ *jongheun@korea.ac.kr
}

\begin{abstract}
The pristine, NiO-decorated, and $\mathrm{NiO}-$ doped $\mathrm{ZnO}$ nanowires were prepared by vapor phase reaction and their gas sensing characteristics were investigated. The decoration of p-type $\mathrm{NiO}$ on n-type $\mathrm{ZnO}$ nanowires significantly enhanced the responses to volatile organic compounds such as $\mathrm{C}_{2} \mathrm{H}_{5} \mathrm{OH}$ and $\mathrm{HCHO}$. In contrast, the doping of $\mathrm{NiO}$ into the lattice of $\mathrm{ZnO} \mathrm{NW}$ deteriorated the gas sensing characteristics. The enhanced gas sensing characteristics of NiO-decorated $\mathrm{ZnO}$ nanowires were explained by the extension of the electron depletion layer due to the formation of nanoscale $p-n$ junctions between p-type $\mathrm{NiO}$ and n-type $\mathrm{ZnO}$.
\end{abstract}

Key words: Nanowires, Volatile Organic Compounds, Gas Sensors, p-n junctions

\section{Introduction}

Oxide semiconductor nanowire (NW) networks are promising gas sensing materials with high gas response, good stability and fast responding kinetics on account of their high surface area to volume ratio, excellent crystallinity and gas accessible networked structures [1]. The gas sensing characteristics can be enhanced by the the addition of noble metal catalysts [2]. The metal oxide additives can be also used to design a high performance gas sensor via controlling donor density, changing the acid-base properties of surface, and varying electronic interaction between additives and sensing materials. In particular, when the p-type oxide material such as $\mathrm{NiO}$ are added to n-type sensing materials such as $\mathrm{SnO}_{2}$ and $\mathrm{ZnO}$, the p-type additive can either incorporate into n-type semiconductors or form second phase. Accordingly, the incorporation of $\mathrm{Ni}$-species into the lattice of n-type semiconductor and the formation of a secondary $\mathrm{NiO}$ phase will have a completely different impact on the gas sensing behavior, i.e., a change in donor density and an extension of the electron depletion layer near the interface of the $p$-n junction, respectively

In this study, the role of $\mathrm{p}$-type $\mathrm{NiO}$ additive in the gas sensing reaction of n-type $\mathrm{ZnO} N W s$ were determined using three different $\mathrm{ZnO} N W$ network sensors: (1) pristine $\mathrm{ZnO} \mathrm{NW}$ networks; (2) NiO-decorated $\mathrm{ZnO} N W$ networks ( $\mathrm{nnO} \mathrm{NW}$ networks decorated with discrete form of p-type NiO particles, $\mathrm{p}$-n junction) and (c) Ni-doped $\mathrm{ZnO} \mathrm{NW}$ networks (NiO-doped $\mathrm{ZnO}$ networks, incorporation of $\mathrm{Ni}$ into $\mathrm{ZnO}$ lattice).

\section{Experimental}

$\mathrm{ZnO} \mathrm{NWs}$ were grown on the alumina substrates (size: $1.5 \times 1.5 \mathrm{~mm}^{2}$ ) with two $\mathrm{Au}$ electrodes (on its top surface) by thermal evaporation using a mixture of $\mathrm{ZnO}$ powders (99.9\%, Aldrich), graphite powders (<20 micron, Aldrich) and Sn powders (99.8\%, Acros). The source ( $\mathrm{ZnO}$ : graphite: $\mathrm{Sn}=1: 1: 0.01$ by weight $\%$ ) was loaded in the $\mathrm{Al}_{2} \mathrm{O}_{3}$ boat and was located in the center of the quartz tube (diameter: $2.5 \mathrm{~cm}$ ). The alumina substrates were placed $5 \mathrm{~cm}$ downstream from the source. After evacuating the quartz tube to $\sim 9 \times 10^{-2}$ torr using a rotary pump, the furnace temperature was increased to $900^{\circ} \mathrm{C}$. The NiOdecorated $\mathrm{ZnO} \mathrm{NWs}$ were prepared using the following procedures. The as-grown $\mathrm{ZnO} \mathrm{NWs}$ on the patterned $\mathrm{Al}_{2} \mathrm{O}_{3}$ substrates and $\mathrm{NiCl}_{2}$ powders $(99.99 \%$, Aldrich) were placed in the left and right part of $\mathrm{Al}_{2} \mathrm{O}_{3}$ boat (length $4 \mathrm{~cm}$ ), respectively. After evacuating the quartz tube to $\sim 9 \times 10^{-2}$ torr using a rotary pump, the furnace temperature was increased to $500{ }^{\circ} \mathrm{C}$. The lenticular/angular configuration of nano-scale $\mathrm{NiO}$ islands could be coated on the surface of the $\mathrm{ZnO}$ NWs by a reaction between the source and $\mathrm{Ar}$ gas (Ar: $200 \mathrm{sccm}$ ). The Ni-doped $\mathrm{ZnO}$ NWs were prepared using 2 zone quartz tube reactor. $\mathrm{NiCl}_{2}$ (99.99\%, Aldrich) powders were 
located at the $1^{\text {st }}$ zone (temperature: $600{ }^{\circ} \mathrm{C}$ ). The mixture between $\mathrm{ZnO}$ powders (99.9\%, Aldrich), graphite powders (< 20 micron, Aldrich) and Sn powders (99.8\%, Acros) were located at the $2^{\text {nd }}$ zone (temperature: $900{ }^{\circ} \mathrm{C}$ ). An alumina substrate was located on the top of the mixture. The distance between $\mathrm{NiCl}_{2}$ and the mixture $10 \mathrm{~cm}$. Argon gas was flowed while increasing or decreasing the temperature of the reactor. The Ni-doped $\mathrm{ZnO} \mathrm{NWs}$ were formed by a reaction between the sources and $\mathrm{Ar}-\mathrm{O}_{2}$ mixture gas ( $\mathrm{Ar}: 100 \mathrm{sccm}, \mathrm{O}_{2}: 1 \mathrm{sccm}$ ).

\section{Result and Discussion}

The ZnO NWs were grown directly on the alumina substrate with two gold electrodes and discrete configuration of $\mathrm{NiO}$ nanoclusters were decorated on $\mathrm{ZnO} \mathrm{NWs}$ by vapor phase reaction (Fig. 1a). The gold electrodes acted as a catalyst for the growth of $\mathrm{ZnO} N W s$ by the vapor-liquid-solid mechanism, which facilitated networking between NWs with highly porous structures and increased the connectivity between the electrodes and NWs. The NiOdecorated $\mathrm{ZnO}$ NWs were $30-70 \mathrm{~nm}$ thick (Fig. 1b).

Pristine $\mathrm{ZnO}$ NWs showed the clean surface and were identified as single crystalline ones (Fig. 2a). The surfaces of NiO-doped NWs were also clean (not shown). Figure $2 b$ shows the TEM image of NiO-deocorated $\mathrm{ZnO} N W s$. The $\mathrm{NiO}$ nanoparticles were uniformly formed on the surface of $\mathrm{ZnO} N W s$, and the size of $\mathrm{NiO}$ nanparticles ranged from 10 to $40 \mathrm{~nm}$. In the lattice-resolved TEM image (Fig. 2c), of the

$\mathrm{NiO}$-decorated $\mathrm{ZnO} \mathrm{NWs}$, the $\left(01^{-}, 10\right)$ fringes of $\mathrm{ZnO}$ were seperated by $2.81 \AA$ and the (220) fringes of $\mathrm{NiO}$ nanoparticles were seperated by $1.47 \AA$ (Fig. 3(c)). This indicates that rough surfaces of NWs in Fig. 1b emanate from the formation of $\mathrm{NiO}$ nanoclusters.

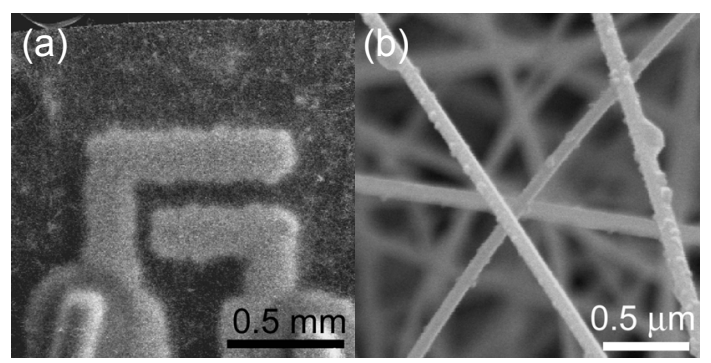

Fig. 1: SEM images of NiO-decorated $\mathrm{ZnO}$ nanowire sensor on alumina substrate

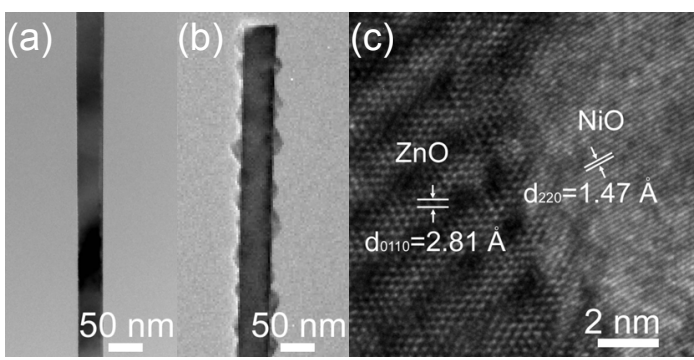

Fig. 2: TEM images of (a) pristine ZnO NW; (b) and (c) NiO-decorated $\mathrm{ZnO} \mathrm{NW}$

The high-angle annular dark field (HAADF) scanning TEM (STEM) image and the elemental mapping of $\mathrm{Zn}, \mathrm{Ni}$ and $\mathrm{O}$ (Fig. 3) by the energy dispersive $\mathrm{X}$-ray spectroscopy (EDS) clearly showed the nanoparticles on the surface of the $\mathrm{ZnO} \mathrm{NW}$ to be $\mathrm{NiO}$. Both the lattice image (Fig. 2c) and the compositional profile (Fig. 3) indicates the distinct interface between $\mathrm{ZnO} \mathrm{NW}$ and $\mathrm{NiO}$ nanoparticles.

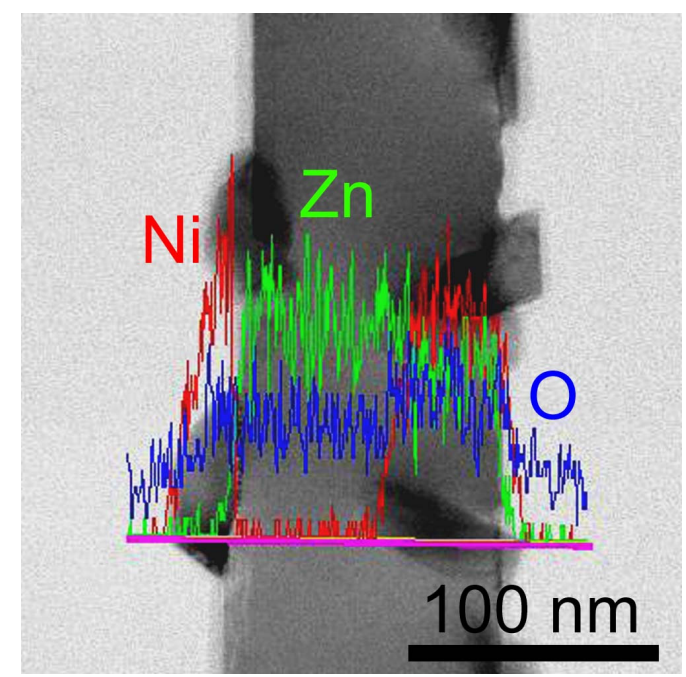

Fig.3: High-angle annular dark field (HAADF) scanning TEM (STEM) image and EDS elemental mapping of $\mathrm{Zn}, \mathrm{Ni}$, and $\mathrm{O}$

The formation of discrete $\mathrm{NiO}$ nanoclusters and the incorporation of $\mathrm{Ni}$ into $\mathrm{ZnO}$ lattice in $\mathrm{NiO}$-decorated $\mathrm{ZnO} \mathrm{NWs}$ and $\mathrm{Ni}$-doped $\mathrm{ZnO}$ NWs, respectively, were verfied by X-ray diffraction (XRD), scanning electron microscopy (SEM), transmission electron microscopy (TEM), X-ray photoelectron spectroscopy (XPS), photoluminescence (PL), and the sensor resistance in air.

The gas responses of pristine, $\mathrm{NiO}$-decorated and $\mathrm{Ni}$-doped $\mathrm{ZnO} \mathrm{NW}$ network sensors to 5 ppm $\mathrm{C}_{2} \mathrm{H}_{5} \mathrm{OH}, \mathrm{HCHO}, \mathrm{CH}_{3} \mathrm{CHO}, \mathrm{CO}, \mathrm{C}_{3} \mathrm{H}_{8}, \mathrm{H}_{2}$, benzene, toluene, and p-xylene were measured at $450{ }^{\circ} \mathrm{C}$. All the sensors showed n-type gas 
sensing behaviors. In particular, n-type gas sensing in $\mathrm{NiO}$-decorated $\mathrm{ZnO} \mathrm{NWs}$ confirms that conduction occurs along continuous n-type $\mathrm{ZnO} \mathrm{NWs}$ rather than the discrete configuration of p-type $\mathrm{NiO}$ nanoparticles. Regardless of sensors, the responses to $\mathrm{C}_{2} \mathrm{H}_{5} \mathrm{OH}$ and $\mathrm{HCHO}$ were higher than those to other gases. However, the abosolute values of gas response were significantly different according to the sensor configuration. The response $\left(R_{a} / R_{g}, R_{a}\right.$ : resistance in air and $R_{g}$ : resistance in gas) to 5 ppm $\mathrm{C}_{2} \mathrm{H}_{5} \mathrm{OH}$ of $\mathrm{NiO}$-decorated $\mathrm{ZnO} \mathrm{NWs}$ at $450{ }^{\circ} \mathrm{C}$ was 29.04 , which was 7.96 -fold higher than that of pristine ZnO NWs (3.65) (Fig. 4). It is interesting that the doping of $\mathrm{NiO}$ deteriorated the response to $5 \mathrm{ppm} \mathrm{C}_{2} \mathrm{H}_{5} \mathrm{OH}$ down to 2.18.

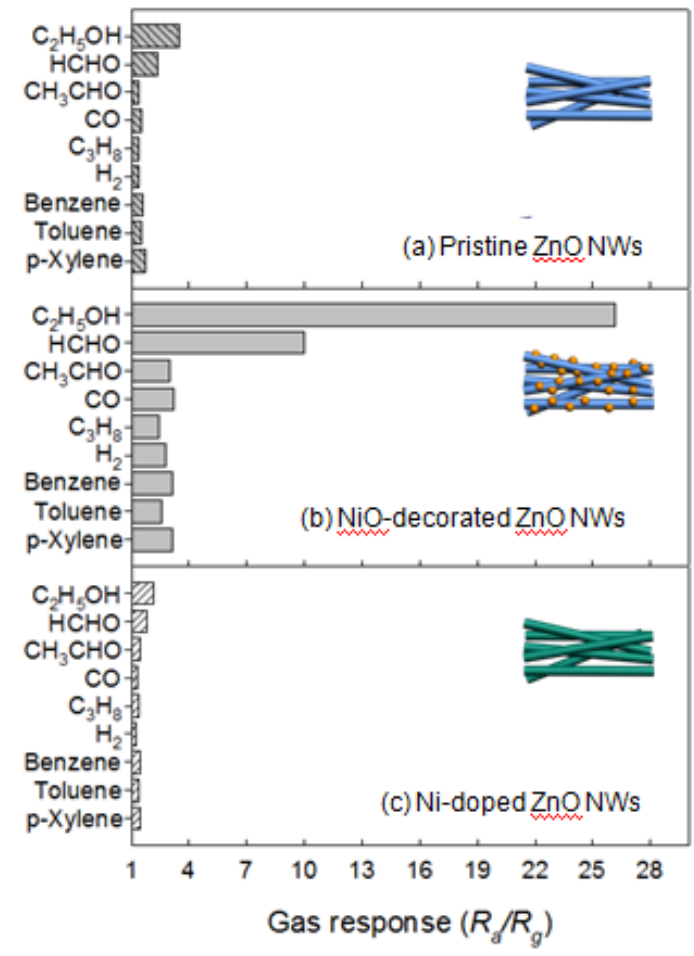

Fig. 4: Gas responses $\left(R_{a} / R_{g}, R_{a}\right.$ : resistance in air and $R_{g}$ : resistance in gas) to $\mathrm{C}_{2} \mathrm{H}_{5} \mathrm{OH}, \mathrm{HCHO}$, $\mathrm{CH}_{3} \mathrm{CHO}, \mathrm{CO}, \mathrm{C}_{3} \mathrm{H}_{8}, \mathrm{H}_{2}$, benzene, toluene, and $\mathrm{p}$ xylene at $450^{\circ} \mathrm{C}$.

The doping of Ni to ZnO NWs decreased the $R_{a}$ value and deteriorated gas sensing characteristics. It has been reported by He et al, that the electrical conductivity of $\mathrm{Ni}$-doped $\mathrm{ZnO}$ NWs was 10-20 times higher than that of pristine $\mathrm{ZnO} \mathrm{NWs}$ due to the co-existence of $\mathrm{Ni}^{3+}$ and $\mathrm{Ni}^{2+}$ [3]. In contrast, the decoration of p-type $\mathrm{NiO}$ nanoparticles on n-type $\mathrm{ZnO} \mathrm{NWs}$ increased the $R_{a}$ value two orders of magnitude by the extension of electron depletion layer near the $p-n$ junction and greatly enhanced the responses and selectivity to $\mathrm{C}_{2} \mathrm{H}_{5} \mathrm{OH}$ and $\mathrm{HCHO}$ (Fig. 3). This clearly indicates that the sensing mechanisms of $\mathrm{NiO}$-decorated and $\mathrm{Ni}$ doped ZnO NW sensors should be understood in the completely different framework.

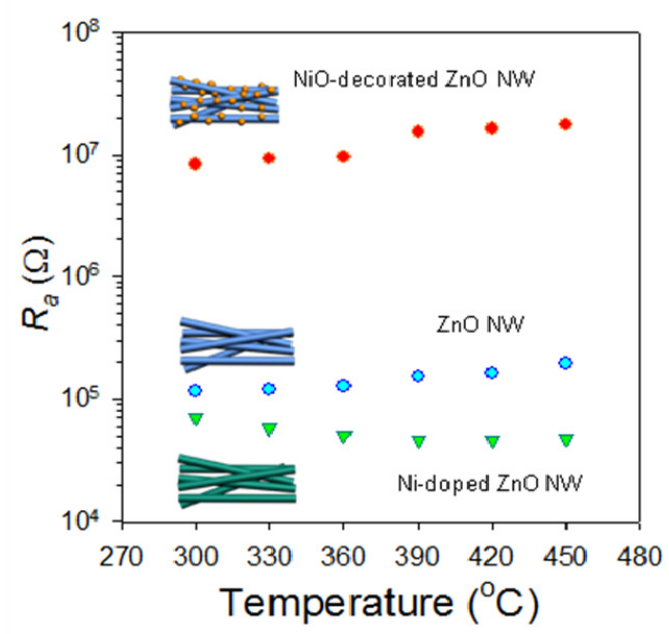

Fig. 5: Resistance in air $\left(R_{a}\right)$ values of NiOdecorated $\mathrm{ZnO} N W, \mathrm{ZnO} N W$, and Ni-doped $\mathrm{ZnO}$ NW

\section{Summary}

The role of $\mathrm{NiO}$ in the gas sensing characteristics of $\mathrm{ZnO}$ nanowires was investigated. The gas response and selectivity to $\mathrm{C}_{2} \mathrm{H}_{5} \mathrm{OH}$ and $\mathrm{HCHO}$ were significantly by the decoration of $\mathrm{NiO}$ nanoclusters on $\mathrm{ZnO}$ nanowires. In contrast, gas responses $\mathrm{C}_{2} \mathrm{H}_{5} \mathrm{OH}$ and $\mathrm{HCHO}$ were deteriorated by the incorporation of $\mathrm{NiO}$ into $\mathrm{ZnO}$ lattice. The enhancement of gas responses was attributed to the extension of electron depletion layer near the $p-n$ junctions.

\section{References}

[1] I. -S. Hwang, J. -H. Lee, J. Nanoeng. Nanomanuf. 1, 4-17 (2011)

[2] A. Kolmakov, D. Klenov, Y. Lilach, S. Stemmer, and M. Moskovits, Adv. Mater., 5, 667 (2005)

[3] H. He, C. S. Lao, L. J. Chen, D. Davidovic, Z. L. Wang, J. Am. Chem. Soc., 127, 16376 (2005) 